\title{
DIFERENCIAIS REGIONAIS E SETORIAIS NA INDÚSTRIA BRASILEIRA
}

\author{
João Saboia ${ }^{\S}$ \\ Lucia Kubrusly
}

\begin{abstract}
RESUMO
$\mathrm{O}$ artigo desenvolve dois tipos de índices que permitem desagregar e comparar a indústria de transformação e extrativa mineral em termos regionais e setoriais. Inicialmente, é apresentado um índice bastante simples, baseado na metodologia do Índice de Desenvolvimento Humano (IDH). Em seguida, a partir de técnicas de componentes principais, é proposto um índice mais elaborado. A utilização dos dois índices mostra resultados coerentes, confirmando os diferenciais setoriais e regionais existentes na indústria brasileira. Por outro lado, a utilização da análise de grupamento permite agregar os diversos segmentos industriais segundo seu nível de desenvolvimento.
\end{abstract}

Palavras-chave: indústria brasileira, descentralização industrial, diferenciais regionais da indústria.

\section{ABSTRACT}

Two indicators for the Brazilian industry are developed. The first one uses a methodology similar to that of the Human Development Index, while the second one is based on multivariate statistics techniques. Both confirm the existence of important regional inequalities in Brazilian industry. The application of cluster analysis to the data separates the industry in various groups according to its level of development.

Keywords: Brazilian industry, industrial decentralization, industrial regional differences.

JEL classification: C43, L60, L70, O18, R12.

\footnotetext{
$\S \quad$ Professor Titular do Instituto de Economia da Universidade Federal do Rio de Janeiro. E-mail: saboia@superig.com.br. a Professora Adjunta do Instituto de Economia da Universidade Federal do Rio de Janeiro. E-mail: luciak@alternex.com.br. Endereço para contato: Instituto de Economia/UFRJ, Av. Pasteur 250, CEP:22290-240, Rio de Janeiro, RJ.

Recebido em junho de 2007. Aceito para publicação em fevereiro de 2008.
} 


\section{INTRODUÇÃo}

Muitos autores têm estudado o fenômeno dos deslocamentos regionais ocorridos na economia brasileira, em especial no setor industrial. Embora as atividades econômicas continuem concentradas na região Sudeste, especialmente no Estado de São Paulo, teria havido um processo de descentralização em direção às regiões menos desenvolvidas e ao interior dos Estados. Enquanto alguns acreditam na continuidade do processo de descentralização, outros identificam sinais de reversão da tendência observada no passado. Por outro lado, busca-se entender as razões que têm motivado os deslocamentos regionais ocorridos na atividade econômica nas últimas décadas. ${ }^{1}$

Diversas explicações têm sido levantadas para os deslocamentos pelos especialistas que estudam o tema. Entre elas, podem ser mencionadas: a busca por regiões, onde os salários são mais baixos; o deslocamento para locais distantes dos centros metropolitanos, onde a mão-de-obra e os sindicatos são menos organizados; os diversos incentivos fiscais ou de outra natureza oferecidos pelos governos locais; a atração da região Sul, por estar próxima dos principais centros consumidores e dos países do Mercosul, e a localização nas proximidades das fontes de matérias-primas, como no caso da região Centro-Oeste, que teriam atraído atividades ligadas à agroindústria com o deslocamento da fronteira agrícola do País.

Tendo em vista os motivos apontados para os deslocamentos espaciais da indústria brasileira nos últimos anos, estaria ocorrendo uma tendência a uma maior homogeneidade regional. As regiões receptoras de novas empresas industriais estariam recebendo novas plantas, em princípio mais modernas que as existentes na origem. Por outro lado, com a maior demanda por mão-de-obra local, haveria uma elevação dos níveis salariais nas regiões menos desenvolvidas, aproximando-se do encontrado nas áreas mais desenvolvidas. ${ }^{2}$ Seria, portanto, de se esperar uma menor heterogeneidade na comparação das empresas de um determinado setor entre as diferentes regiões.

Numa outra vertente, inúmeros estudos foram realizados no Brasil na última década, desde o trabalho pioneiro de Ferraz, Kupfer e Haguenauer (1995) sobre a indústria brasileira após o processo de abertura da economia. Tais trabalhos procuram determinar o nível de produtividade e competitividade, além da heterogeneidade existente entre os diferentes setores industriais, buscando entender as razões para os resultados encontrados. ${ }^{3}$

Este artigo se coloca na confluência dos estudos voltados, de um lado, para os aspectos regionais e, de outro, para as características setoriais da indústria brasileira. Trata-se de utilizar procedimentos estatísticos relativamente simples para verificar "semelhanças e diferenças" entre a indústria dos distintos setores e regiões do País. Busca-se com isso confirmar ou não os desníveis existentes tanto entre setores industriais quanto entre regiões. ${ }^{4}$

1 Ver, por exemplo, Diniz e Crocco (1996), Cano (1997), Pacheco (1999), Andrade e Serra (2000), Saboia (2000 e 2001), Caiado (2002), Ramos e Ferreira (2005a e 2005b) e Rezende e Willie (2005). Enquanto a maior parte dos estudos é específica da indústria, alguns tratam da economia em geral.

2 Para uma discussão sobre as admissões na indústria com enfoque regional ver, por exemplo, Senai (2007).

3 Ver, por exemplo, Salm, Saboia e Carvalho (1997), Ferraz, Kupfer e Iootty (2004) e Kupfer e Rocha (2004).

4 Diferentemente de parcela da bibliografia mencionada acima, este artigo está menos voltado para a discussão do processo de descentralização em si, e mais para a diferenciação regional e setorial da indústria, seguindo a linha desenvolvida em Saboia (2001). A principal novidade é a utilização de técnicas estatísticas multivariadas num período mais recente e com um maior nível de desagregação industrial. 
Com este objetivo, a indústria de transformação e extrativa mineral é desagregada segundo o conceito de "divisão", sendo representada por um total de 27 segmentos industriais. ${ }^{5}$ A fonte de dados é a Relação Anual de Informações Sociais (RAIS) para o ano de 2005. Três características dos trabalhadores (remuneração, escolaridade e ocupação) são utilizadas para a determinação do nível de desenvolvimento da indústria. Supõe-se que os setores "mais desenvolvidos" nas diferentes regiões são aqueles que pagam os melhores salários, empregam a mão-de-obra mais escolarizada e possuem os maiores porcentuais de trabalhadores técnicos e científicos. ${ }^{6}$ Em outras palavras, remuneração, escolaridade e incidência de trabalhadores técnicos ou científicos estão claramente associadas com a produtividade da indústria, sendo utilizadas como proxies para determinar seu nível de desenvolvimento.

Para a comparação intersetorial/regional, as três variáveis referentes às características dos trabalhadores são transformadas em indicadores da indústria, utilizando-se duas técnicas distintas. Inicialmente, de maneira bem simples, por meio de metodologia similar à utilizada no Índice de Desenvolvimento Humano (IDH) da ONU. Em seguida, com o uso de técnicas de estatística multivariada (análise de componentes principais e de grupamentos), que permitem não apenas a ordenação dos setores industriais como também sua agregação em conjuntos de setores "semelhantes". Como será visto adiante, as duas metodologias fornecem resultados coerentes e se complementam. Esse é um dos principais ensinamentos do artigo, mostrando que um tratamento de dados extremamente simples pode produzir resultados confiáveis, semelhantes aos obtidos com técnicas mais elaboradas.

Além desta introdução, o artigo possui mais quatro seções. Na próxima, são apresentados e discutidos os dados utilizados no trabalho. A Seção 3 apresenta a primeira versão dos indicadores, enquanto, na Seção 4, é desenvolvida a análise multivariada, permitindo a ordenação e o agrupamento dos setores industriais, bem como uma comparação entre os indicadores encontrados por meio das duas metodologias, com resultados obtidos por outros autores e também com dados de produtividade da indústria. Finalmente, na Seção 5, são apresentados os comentários finais, as principais conclusões e algumas sugestões de extensão do trabalho.

\section{APRESENTAÇÃO DOS DADOS UTILIZADOS}

Nesta seção são apresentados os dados da RAIS, que servem de referência para o restante do trabalho. Conforme mencionado acima, foi escolhido o ano de 2005 para ilustrar os resultados,

5 Divisão representa um nível intermediário de desagregação das atividades econômicas sendo utilizada pelas instituições produtoras de estatísticas econômicas brasileiras. A economia está dividida em 59 divisões. A indústria de transformação possui 23 divisões e a extrativa mineral quatro divisões.

6 A lista de variáveis que poderiam ser utilizadas no trabalho é extensa, tais como o valor adicionado, a produtividade, a lucratividade, as exportações, etc. Seu levantamento desagregado em termos setoriais e regionais, entretanto, nem sempre é tarefa simples e a qualidade dos dados disponíveis é desigual. Desta forma, embora reconhecendo as limitações dos dados da RAIS, optou-se pela utilização de uma única fonte de dados para minorar as dificuldades.

7 Deve-se reconhecer, entretanto, que não estão sendo incluídas no estudo variáveis específicas dos "resultados" das empresas, o que abre a possibilidade para alguma distorção nos resultados. Assim, é possível que algum setor apresente trabalhadores relativamente bem remunerados e escolarizados sem que isso represente obrigatoriamente um elevado nível de produtividade e competitividade naquele setor. De qualquer forma, como será visto mais adiante no texto, os resultados encontrados com os indicadores desenvolvidos no artigo são coerentes com os dados de produtividade. 
sendo utilizados os dados de emprego, remuneração média, escolaridade e ocupação dos trabalhadores. Trata-se do ano mais recente com dados disponíveis por ocasião da preparação deste texto.

\subsection{Emprego}

Segundo a RAIS, havia 6.155.901 empregados na indústria de transformação e extrativa mineral em 2005. Conforme esperado, há uma grande concentração regional do emprego. Mais da metade encontra-se na região Sudeste, cerca de um quarto na região Sul, um oitavo na região Nordeste e o restante nas regiões Norte e Centro-Oeste.

As regiões Sul e Sudeste são as mais diversificadas, distribuindo-se os trabalhadores por praticamente todos os segmentos industriais. Nas demais regiões, há concentração do emprego em poucas divisões. Na região Nordeste, $55 \%$ dos trabalhadores são encontrados em apenas três divisões - produtos alimentícios e bebidas; produtos de couros e calçados, e vestuário. Na região Centro-Oeste, $42 \%$ do emprego industrial concentra-se em produtos alimentícios e bebidas. Na região Norte, 52\% dos trabalhadores também pertencem a apenas três divisões - produtos alimentares e bebidas; produtos de madeira, e fabricação de material eletrônico e aparelhos de comunicação (Tabela 1).

\subsection{Remuneração}

Há grandes desníveis entre as remunerações nas várias regiões e setores da indústria. O nível médio varia entre R\$702 na região Nordeste e R\$1370 no Sudeste. Em termos setoriais, os valores extremos são encontrados na extração de petróleo ( $\mathrm{R}$ \$ 5492) e na confecção de artigos de vestuário ( $\mathrm{R}$ \$ 514), uma relação de mais de dez para um.

Em geral, os diferenciais de rendimento inter-regionais de cada segmento da indústria são elevados. No caso da indústria de extração de petróleo e gás natural, por exemplo, o rendimento médio chegava a $\mathrm{R} \$ 7072$ na região Norte, enquanto não passava de $\mathrm{R} \$ 1045$ na região Centro-Oeste. Em outros casos, como na indústria de couros e calçados e na confecção de artigos de vestuário, há certa uniformidade nos baixos salários pagos nas diferentes regiões.

A Tabela 2 ilustra os diferenciais nos níveis médios de remuneração nas diferentes divisões da indústria de transformação e extrativa mineral nas distintas regiões. Se compararmos os valores máximo e mínimo nas diversas regiões e divisões, verificamos que, enquanto o trabalhador na extração de petróleo na região Norte ganha em média $\mathrm{R} \$ 7072$, a remuneração média do trabalhador da extração de carvão na região Nordeste não passa de $\mathrm{R} \$ 381$. Tais dados não chegam a surpreender, tendo em vista a conhecida má distribuição da renda do trabalho existente no Brasil. 


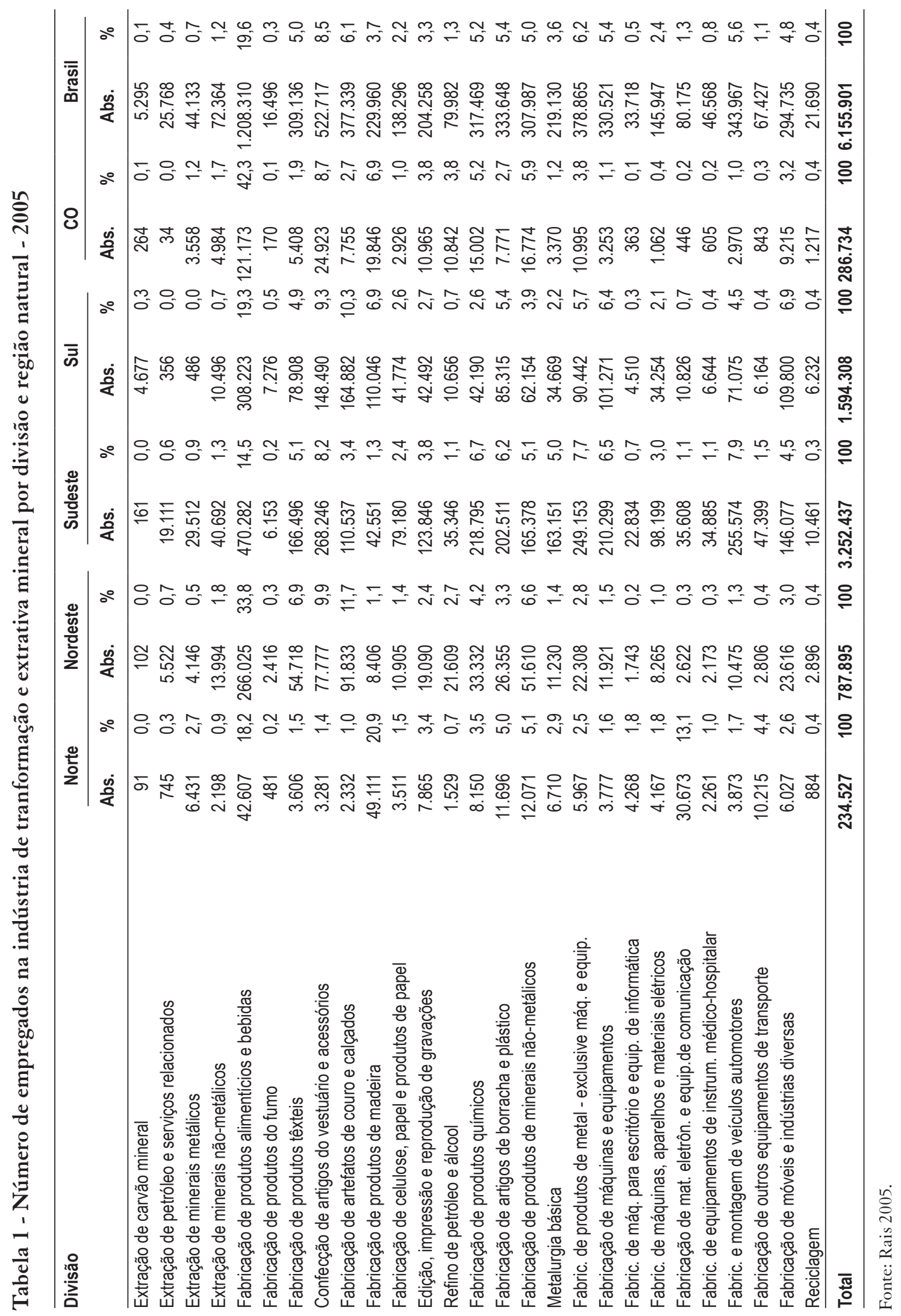


Tabela 2 - Remuneração média (em reais) na indústria de tranformação e extrativa mineral por divisão e região natural - 2005

\begin{tabular}{|c|c|c|c|c|c|c|}
\hline Divisão & N & NE & SE & S & $\mathrm{CO}$ & Brasil \\
\hline Extração de carvão mineral & 453 & 381 & 840 & 1382 & 427 & 1282 \\
\hline Extração de petróleo e serviços relacionados & 7072 & 4216 & 5846 & 3384 & 1045 & 5492 \\
\hline Extração de minerais metálicos & 1843 & 1615 & 1982 & 982 & 1638 & 1889 \\
\hline Extração de minerais não-metálicos & 1270 & 718 & 862 & 783 & 935 & 840 \\
\hline Fabricação de produtos alimentícios e bebidas & 672 & 581 & 1012 & 779 & 696 & 814 \\
\hline Fabricação de produtos do fumo & 972 & 658 & 2100 & 1935 & 1217 & 1774 \\
\hline Fabricação de produtos têxteis & 497 & 587 & 879 & 833 & 585 & 806 \\
\hline Confecção de artigos do vestuário e acessórios & 390 & 390 & 548 & 535 & 427 & 514 \\
\hline Fabricação de artefatos de couro e calçados & 537 & 444 & 572 & 650 & 545 & 574 \\
\hline Fabricação de produtos de madeira & 532 & 418 & 777 & 637 & 593 & 628 \\
\hline Fabricação de celulose, papel e produtos de papel & 1057 & 1001 & 1575 & 1124 & 768 & 1364 \\
\hline Edição, impressão e reprodução de gravações & 947 & 825 & 1563 & 948 & 1076 & 1316 \\
\hline Refino de petróleo e álcool & 2132 & 1603 & 3351 & 1380 & 985 & 2272 \\
\hline Fabricação de produtos químicos & 892 & 1825 & 2280 & 1556 & 932 & 2037 \\
\hline Fabricação de artigos de borracha e plástico & 1016 & 691 & 1208 & 922 & 655 & 1075 \\
\hline Fabricação de produtos de minerais não-metálicos & 556 & 526 & 957 & 801 & 612 & 819 \\
\hline Metalurgia básica & 1451 & 1198 & 1806 & 1347 & 1025 & 1679 \\
\hline Fabric. de produtos de metal - exclusive máq. e equip. & 966 & 693 & 1127 & 961 & 683 & 1047 \\
\hline Fabricação de máquinas e equipamentos & 1126 & 926 & 1663 & 1364 & 974 & 1532 \\
\hline Fabric. de máq. para escritório e equip. de informática & 769 & 943 & 2024 & 2160 & 3934 & 1848 \\
\hline Fabric. de máquinas, aparelhos e materiais elétricos & 920 & 1007 & 1512 & 1103 & 697 & 1365 \\
\hline Fabricação de mat. eletrôn. e equip.de comunicação & 1164 & 953 & 1787 & 1318 & 1109 & 1454 \\
\hline Fabric. de equipamentos de instrum. médico-hospitalar & 1106 & 726 & 1461 & 1210 & 789 & 1365 \\
\hline Fabric. e montagem de veículos automotores & 1098 & 1365 & 2170 & 1666 & 986 & 2019 \\
\hline Fabricação de outros equipamentos de transporte & 1764 & 599 & 2451 & 1350 & 862 & 2149 \\
\hline Fabricação de móveis e indústrias diversas & 784 & 488 & 811 & 695 & 520 & 732 \\
\hline Reciclagem & 464 & 502 & 798 & 586 & 517 & 668 \\
\hline Total & 905 & 702 & 1370 & 902 & 716 & 1115 \\
\hline
\end{tabular}

Fonte: Rais 2005.

\subsection{Escolaridade}

Os diferenciais entre os níveis de escolaridade inter-regionais e intersetoriais são bem menores do que no caso dos rendimentos. Em 2005, o número médio de anos de estudo variava entre 7,5 na 
região Nordeste e 9,1 na região Sudeste, e entre 7,1 na extração de minerais não-metálicos e 11,7 na fabricação de máquinas para escritório e equipamentos de informática e na extração de petróleo. ${ }^{8}$

Apesar da melhoria do nível de escolaridade dos trabalhadores verificada nos últimos anos, a situação continua muito precária em alguns casos, como na extração de carvão mineral no Norte e Nordeste, na fabricação de produtos de madeira no Norte, na fabricação de coque e refino de petróleo no Nordeste e na fabricação de produtos alimentícios e bebidas no Nordeste. Neles, a escolaridade média mal atingia cinco anos de estudo em 2005 (Tabela 3).

A escolaridade dos trabalhadores industriais na região Nordeste tende a ser a mais baixa do País. O número médio de anos de estudo no Nordeste é o mais baixo entre as cinco regiões em 12 divisões. Na comparação com a região Sudeste, a região Nordeste leva a pior em 20 das 27 divisões pesquisadas. Em outras palavras, também na questão da escolaridade dos trabalhadores os diferenciais existentes podem ser considerados elevados.

\subsection{Trabalhadores técnicos e científicos}

A participação de trabalhadores das profissões técnicas e científicas é relativamente baixa na indústria brasileira. ${ }^{9}$ Em 2005, apenas 10,7\% dos trabalhadores faziam parte desse grupo. Em termos regionais, a situação era mais favorável no Sudeste $(12,6 \%)$ e mais precária no Nordeste $(6,8 \%)$.

Em termos setoriais, há grandes desníveis. Na extração de petróleo, de minerais metálicos e na fabricação de máquinas de escritório, de equipamentos de informática e de material eletrônico entre outros, parcela considerável de seus trabalhadores são de nível técnico ou científico. Em contrapartida, são pouquíssimos os empregados com esse nível de qualificação em setores tradicionais como na confecção de artigos de vestuários, couros, calçados, produtos de madeira, etc.

A situação mais favorável é encontrada na extração de petróleo na região Norte, onde mais da metade dos trabalhadores são de nível técnico ou científico. Em contrapartida, a RAIS não levantou nenhum trabalhador técnico ou científico na extração de carvão mineral na região Nordeste (Tabela 4).

8 Embora a RAIS não informe o número de anos de estudo dos trabalhadores, este valor pode ser estimado a partir das informações da RAIS, supondo uma determinada distribuição nas faixas de escolaridade informadas. Às faixas de escolaridade foram atribuídos os seguintes anos médios de estudo: analfabetos $=0 ; 4^{\mathrm{a}}$ série incompleta $=2 ; 4^{\mathrm{a}}$ série completa $=4 ; 8^{\mathrm{a}}$ série incompleta $=6 ; 8^{\mathrm{a}}$ série completa $=8 ; 2^{\circ}$ grau incompleto $=9,5 ; 2^{\circ}$ grau completo $=11$; superior incompleto $=13$ e superior completo $=15,5$ anos.

9 Foram usados os grandes grupos 2 e 3 da Classificação Brasileira de Ocupações (CBO) 2002 para representar os trabalhadores técnicos e científicos em 2005. O grande grupo 2 agrega os empregos que compõem as profissões científicas e das artes de nível superior e o grande grupo 3 os que compõem as profissões técnicas de nível médio. 
Tabela 3 - Anos de estudo na indústria de tranformação e extrativa mineral por divisão e região natural - 2005

\begin{tabular}{|c|c|c|c|c|c|c|}
\hline Divisão & N & NE & SE & S & $\mathrm{CO}$ & Brasil \\
\hline Extração de carvão mineral & 5,0 & 5,3 & 6,8 & 8,0 & 6,3 & 7,8 \\
\hline Extração de petróleo e serviços relacionados & 11,8 & 11,2 & 11,8 & 10,8 & 9,3 & 11,7 \\
\hline Extração de minerais metálicos & 9,9 & 9,1 & 10,5 & 7,1 & 9,4 & 10,1 \\
\hline Extração de minerais não-metálicos & 8,2 & 6,7 & 7,1 & 7,1 & 8,1 & 7,1 \\
\hline Fabricação de produtos alimentícios e bebidas & 7,9 & 5,7 & 8,4 & 8,3 & 8,0 & 7,7 \\
\hline Fabricação de produtos do fumo & 9,6 & 6,5 & 10,6 & 10,5 & 9,4 & 9,9 \\
\hline Fabricação de produtos têxteis & 7,8 & 8,4 & 8,4 & 8,5 & 8,7 & 8,4 \\
\hline Confecção de artigos do vestuário e acessórios & 9,0 & 8,4 & 8,4 & 8,6 & 8,6 & 8,5 \\
\hline Fabricação de artefatos de couro e calçados & 7,0 & 8,5 & 8,3 & 7,3 & 8,0 & 7,9 \\
\hline Fabricação de produtos de madeira & 5,5 & 6,9 & 7,9 & 7,2 & 6,5 & 6,9 \\
\hline Fabricação de celulose, papel e produtos de papel & 9,7 & 9,3 & 9,5 & 8,9 & 9,4 & 9,3 \\
\hline Edição, impressão e reprodução de gravações & 10,6 & 10,4 & 10,3 & 10,2 & 10,4 & 10,3 \\
\hline Refino de petróleo e álcool & 6,3 & 5,2 & 9,3 & 7,4 & 6,7 & 7,5 \\
\hline Fabricação de produtos químicos & 7,4 & 9,6 & 10,6 & 10,1 & 9,9 & 10,3 \\
\hline Fabricação de artigos de borracha e plástico & 10,3 & 8,9 & 9,1 & 8,9 & 8,8 & 9,1 \\
\hline Fabricação de produtos de minerais não-metálicos & 7,0 & 6,2 & 7,9 & 7,8 & 7,4 & 7,5 \\
\hline Metalurgia básica & 9,1 & 8,9 & 9,4 & 9,2 & 8,7 & 9,4 \\
\hline Fabric. de produtos de metal - exclusive máq. e equip. & 9,8 & 8,5 & 8,8 & 8,8 & 8,5 & 8,8 \\
\hline Fabricação de máquinas e equipamentos & 10,9 & 9,3 & 9,7 & 9,7 & 9,4 & 9,7 \\
\hline Fabric. de máq. para escritório e equip. de informática & 11,0 & 10,9 & 11,9 & 11,9 & 12,3 & 11,7 \\
\hline Fabric. de máquinas, aparelhos e materiais elétricos & 10,8 & 10,1 & 9,8 & 10,0 & 9,3 & 9,9 \\
\hline Fabricação de mat. eletrôn. e equip.de comunicação & 11,1 & 10,9 & 10,5 & 10,6 & 10,6 & 10,8 \\
\hline Fabric. de equipamentos de instrum. médico-hospitalar & 10,5 & 10,0 & 10,3 & 10,4 & 10,4 & 10,3 \\
\hline Fabric. e montagem de veículos automotores & 10,4 & 10,3 & 10,0 & 10,0 & 9,6 & 10,0 \\
\hline Fabricação de outros equipamentos de transporte & 10,6 & 8,9 & 10,1 & 9,2 & 9,3 & 10,0 \\
\hline Fabricação de móveis e indústrias diversas & 9,1 & 8,2 & 8,6 & 8,4 & 8,3 & 8,5 \\
\hline Reciclagem & 8,2 & 7,8 & 7,9 & 7,6 & 7,8 & 7,8 \\
\hline Total & 8,5 & 7,5 & 9,1 & 8,6 & 8,2 & 8,7 \\
\hline
\end{tabular}

Fonte: Rais 2005. 
Tabela 4 - Porcentual de trabalhadores técnicos das profissões técnicas e cientificas da indústria de tranformação e extrativa mineral por divisão e região natural - 2005

\begin{tabular}{|c|c|c|c|c|c|c|}
\hline Divisão & $\mathbf{N}$ & NE & SE & S & $\mathrm{CO}$ & Brasil \\
\hline Extração de carvão mineral & 3,3 & 0,0 & 5,0 & 6,8 & 3,0 & 6,4 \\
\hline Extração de petróleo e serviços relacionados & 54,9 & 27,0 & 40,1 & 46,1 & 29,4 & 37,8 \\
\hline Extração de minerais metálicos & 25,0 & 18,5 & 30,9 & 6,2 & 15,6 & 27,3 \\
\hline Extração de minerais não-metálicos & 15,0 & 6,2 & 5,7 & 4,3 & 8,3 & 6,1 \\
\hline Fabricação de produtos alimentícios e bebidas & 6,6 & 4,4 & 8,4 & 6,5 & 8,0 & 6,9 \\
\hline Fabricação de produtos do fumo & 15,4 & 9,7 & 24,6 & 23,1 & 28,8 & 21,5 \\
\hline Fabricação de produtos têxteis & 8,3 & 7,1 & 7,4 & 8,0 & 6,2 & 7,5 \\
\hline Confecção de artigos do vestuário e acessórios & 2,8 & 3,3 & 5,1 & 4,4 & 3,1 & 4,5 \\
\hline Fabricação de artefatos de couro e calçados & 4,1 & 2,9 & 4,2 & 3,2 & 5,5 & 3,5 \\
\hline Fabricação de produtos de madeira & 2,9 & 2,2 & 4,9 & 3,3 & 2,1 & 3,3 \\
\hline Fabricação de celulose, papel e produtos de papel & 11,3 & 11,0 & 14,3 & 8,4 & 7,3 & 12,0 \\
\hline Edição, impressão e reprodução de gravações & 18,4 & 18,9 & 18,1 & 16,3 & 18,9 & 17,8 \\
\hline Refino de petróleo e álcool & 9,9 & 9,1 & 26,5 & 9,8 & 5,8 & 16,4 \\
\hline Fabricação de produtos químicos & 7,6 & 16,8 & 22,5 & 18,7 & 13,1 & 20,6 \\
\hline Fabricação de artigos de borracha e plástico & 21,5 & 16,0 & 12,4 & 9,8 & 8,6 & 12,3 \\
\hline Fabricação de produtos de minerais não-metálicos & 3,3 & 4,6 & 7,2 & 5,5 & 3,8 & 6,1 \\
\hline Metalurgia básica & 12,5 & 12,8 & 16,9 & 13,4 & 9,9 & 15,9 \\
\hline Fabric. de produtos de metal - exclusive máq. e equip. & 11,4 & 7,2 & 9,6 & 8,2 & 6,0 & 9,0 \\
\hline Fabricação de máquinas e equipamentos & 18,3 & 12,0 & 16,3 & 15,2 & 11,0 & 15,8 \\
\hline Fabric. de máq. para escritório e equip. de informática & 12,1 & 22,3 & 36,9 & 35,4 & 37,7 & 32,8 \\
\hline Fabric. de máquinas, aparelhos e materiais elétricos & 13,7 & 14,1 & 16,5 & 13,3 & 14,3 & 15,5 \\
\hline Fabricação de mat. eletrôn. e equip.de comunicação & 18,8 & 39,9 & 22,4 & 25,7 & 46,2 & 22,2 \\
\hline Fabric. de equipamentos de instrum. médico-hospitalar & 22,3 & 19,6 & 23,5 & 23,9 & 22,6 & 23,3 \\
\hline Fabric. e montagem de veículos automotores & 14,3 & 12,8 & 15,1 & 16,0 & 10,9 & 15,2 \\
\hline Fabricação de outros equipamentos de transporte & 19,7 & 6,3 & 26,0 & 20,5 & 11,5 & 23,6 \\
\hline Fabricação de móveis e indústrias diversas & 7,3 & 4,3 & 6,1 & 4,3 & 4,5 & 5,3 \\
\hline Reciclagem & 3,7 & 5,6 & 5,1 & 6,6 & 4,2 & 5,5 \\
\hline Total & 10,8 & 6,8 & 12,6 & 8,2 & 7,6 & 10,4 \\
\hline
\end{tabular}

Fonte: Rais 2005. 


\section{3 ÍNDICES DE DESENVOLVIMENTO REGIONAIS E SETORIAIS}

Utiliza-se, nesta seção, metodologia semelhante à desenvolvida em Saboia (2001), inspirada no cálculo do IDH. A principal diferença com o trabalho mencionado é o fato de se considerar a classificação setorial de divisões, que desagrega a indústria de transformação e extrativa mineral em 27 setores. $^{10}$

São utilizadas as três variáveis informadas pela RAIS, apresentadas na Seção 2 - remuneração média, escolaridade e ocupações técnicas e científicas $(\mathrm{CBO})$

O índice de remuneração para o setor $i$ na região $j$ (IWij) é construído a partir da equação

$$
I W i j=(\text { Wij }-W \min ) /(W \max -W \min )
$$

Sendo

Wij - remuneração média no setor $i$ na região $j$;

Wmax - remuneração média máxima entre os setores e regiões;

Wmin - remuneração média mínima entre os setores e regiões.

Analogamente, pode-se obter o índice de escolaridade IEij e de ocupações técnicas e científicas IOij para o setor $i$ na região $j$. $^{11}$

Pode-se verificar facilmente que os índices construídos variam no intervalo entre zero e a unidade. Quanto maior seu valor melhor é a situação representada pelo índice.

O índice de desenvolvimento IDij para o setor $i$ na região $j$ pode ser calculado pela média aritmética dos três índices parciais i.e. ${ }^{12}$

$$
I D i j=(I W i j+I E i j+I O i j) / 3
$$

Utilizando-se esta metodologia, foram estimados os índices de desenvolvimento da indústria em $2005 .^{13}$

Conforme esperado, os índices são mais favoráveis na região Sudeste, que concentra a indústria mais desenvolvida do País. Em segundo lugar, nas regiões Norte e Sul. Finalmente, nas re-

10 Saboia (2001) utilizou a classificação de subsetores, onde a indústria de transformação e extrativa mineral é desagregada em apenas 13 segmentos.

11 Tendo em vista os grandes diferenciais de rendimento e de trabalhadores técnicos e científicos e, em menor escala, de escolaridade, tomou-se os logaritmos das três variáveis antes de se calcular os índices. Trata-se de procedimento usual em cálculos de índices como no próprio IDH.

12 O índice pode também ser obtido por médias aritméticas ponderadas definindo-se os pesos segundo a importância atribuída pelo analista à variável considerada. Os resultados encontrados mais adiante, na Seção 4, confirmam que a escolha arbitrária de pesos iguais para o cálculo do índice é uma "boa" escolha.

13 A única dificuldade para o cálculo do índice foi o tratamento dado ao porcentual de trabalhadores na extração de carvão mineral na região Nordeste, onde o valor encontrado foi zero. Neste caso, atribuiu-se arbitrariamente o valor nulo para o logaritmo antes do cálculo do índice. Tal procedimento equivale a arbitrar em $1 \%$ o porcentual de trabalhadores técnicos e científicos naquele setor e região, representando uma distorção mínima no resultado final. Note-se que o segundo menor porcentual desses trabalhadores foi de $2,1 \%$, encontrado na fabricação de produtos de madeira no Centro-Oeste. 
giões Nordeste e Centro-Oeste. Os valores variaram entre 0,376 no Nordeste e 0,580 no Sudeste ('Tabela 5). ${ }^{14}$

O resultado relativamente favorável encontrado na região Norte $(0,493)$, ligeiramente superior ao da região Sul, está associado ao peso da Zona Franca de Manaus naquela região, abrigando segmentos industriais modernos como material de transporte, mecânica, produtos eletrônicos, etc. Cabe notar que os níveis médios de remuneração e de escolaridade dos trabalhadores na região Norte são muito próximos aos encontrados na região Sul e que, porcentualmente, há mais trabalhadores técnicos e científicos na primeira que na segunda.

A superioridade da região Sudeste em relação às demais é nítida. Em 16 das 27 divisões analisadas, seu índice é o mais elevado. Por outro lado, a região Nordeste apresenta o menor índice em dez divisões.

Em termos setoriais, os diferenciais são bem mais elevados que os regionais, variando entre 0,273 na fabricação de produtos de madeira e 0,922 na extração de petróleo e gás natural. É importante destacar que o fato de um setor apresentar um índice relativamente elevado no País não impede que seja baixo em algumas regiões, como no caso da fabricação de outros equipamentos de transporte, que varia entre 0,417 na região Nordeste e 0,743 na região Sudeste. Os diferenciais regionais são também elevados em vários outros segmentos industriais, como na extração de carvão mineral, extração de minerais metálicos, fabricação de produtos de fumo e fabricação de produtos de madeira, entre outros. Portanto, fica confirmada a heterogeneidade regional existente em diversos segmentos da indústria.

Em contrapartida, há divisões com grande homogeneidade no País. Esse é o caso, por exemplo, da indústria de edição e impressão, que se modernizou muito nos últimos anos, e cujos índices variam entre 0,599 na região Sul e 0,671 na região Sudeste. Alguns segmentos da indústria eletroeletrônica apresentam comportamento similar. A indústria têxtil e de vestuário também apresenta índices relativamente homogêneos, porém com valores bem menores.

Além do setor de extração de petróleo, outros segmentos industriais apresentam índices relativamente favoráveis, confirmando sua melhor situação no interior da indústria. Com índices na faixa entre 0,700 e 0,800, podem ser mencionadas a extração de minerais metálicos, a fabricação de máquinas para escritório e equipamentos de informática, a fabricação de material eletrônico e equipamentos de comunicação, a fabricação de outros equipamentos de transporte e a fabricação de produtos químicos. Outras sete divisões possuem índices com valores superiores a 0,600.

Entre as divisões com os menores índices médios estão segmentos tradicionais como fabricação de produtos de madeira, já mencionado acima, couros, artefatos de couros e calçados $(0,319)$, confecção de artigos de vestuário (0,355), extração de minerais não-metálicos $(0,369)$, reciclagem $(0,370)$ e fabricação de produtos de minerais não-metálicos $(0,389)$, entre outros.

Comparando-se os valores extremos do índice encontrados nas diversas regiões e divisões industriais, encontramos desde 0,015 na extração de carvão mineral no Nordeste, até 0,985 na extra-

14 Apenas para efeito de comparação, foram estimados os índices utilizando peso $2 / 4$ para remuneração e peso $1 / 4$ para as outras duas variáveis. Os valores dos índices são um pouco menores, mas as ordenações permanecem praticamente inalteradas. $\mathrm{Na}$ região Sudeste, por exemplo, foi obtido o valor 0,544 e na Nordeste, 0,334. 
ção de petróleo na região Norte, apontando mais uma vez para os enormes diferenciais existentes na indústria.

Em resumo, verifica-se que efetivamente os desníveis regionais e setoriais na indústria brasileira são extremamente elevados. Se, por um lado, alguns segmentos tradicionais apresentam resultados muito desfavoráveis em algumas regiões do País, por outro, as divisões modernas são o destaque em outras regiões. A grande surpresa são os resultados favoráveis encontrados na região Norte, fato esse que pode ser atribuído à concentração da indústria eletroeletrônica e de transporte na Zona Franca de Manaus, com índices relativamente elevados. Por outro lado, alguns segmentos industriais apresentam relativa proximidade nas várias regiões. Portanto, pelo menos em parte, pode-se afirmar que o processo de descentralização industrial ocorrido nas últimas décadas trouxe alguma homogeneização em segmentos deslocados para regiões menos desenvolvidas do País.

Tabela 5 - Índices de desenvolvimento da indústrias de transformação e extrativa mineral por divisão -2005

\begin{tabular}{|c|c|c|c|c|c|c|}
\hline Divisão & $\mathbf{N}$ & $\mathrm{NE}$ & SE & $\mathbf{S}$ & $\mathrm{CO}$ & Brasil \\
\hline Extração de carvão mineral & 0,119 & 0,015 & 0,338 & 0,479 & 0,189 & 0,454 \\
\hline Extração de petróleo e serviços relacionados & 0,985 & 0,848 & 0,939 & 0,854 & 0,628 & 0,922 \\
\hline Extração de minerais metálicos & 0,701 & 0,628 & 0,748 & 0,389 & 0,629 & 0,720 \\
\hline Extração de minerais não-metálicos & 0,545 & 0,330 & 0,366 & 0,333 & 0,456 & 0,369 \\
\hline Fabricação de produtos alimentícios e bebidas & 0,390 & 0,217 & 0,480 & 0,426 & 0,414 & 0,408 \\
\hline Fabricação de produtos do fumo & 0,578 & 0,345 & 0,741 & 0,723 & 0,645 & 0,685 \\
\hline Fabricação de produtos têxteis & 0,370 & 0,404 & 0,454 & 0,456 & 0,405 & 0,446 \\
\hline Confecção de artigos do vestuário e acessórios & 0,305 & 0,295 & 0,369 & 0,361 & 0,309 & 0,355 \\
\hline Fabricação de artefatos de couro e calçados & 0,282 & 0,303 & 0,351 & 0,298 & 0,356 & 0,319 \\
\hline Fabricação de produtos de madeira & 0,157 & 0,192 & 0,382 & 0,288 & 0,207 & 0,273 \\
\hline Fabricação de celulose, papel e produtos de papel & 0,565 & 0,541 & 0,623 & 0,511 & 0,477 & 0,583 \\
\hline Edição, impressão e reprodução de gravações & 0,626 & 0,606 & 0,671 & 0,599 & 0,635 & 0,650 \\
\hline Refino de petróleo e álcool & 0,471 & 0,362 & 0,750 & 0,481 & 0,358 & 0,587 \\
\hline Fabricação de produtos químicos & 0,409 & 0,654 & 0,742 & 0,664 & 0,569 & 0,711 \\
\hline Fabricação de artigos de borracha e plástico & 0,635 & 0,511 & 0,564 & 0,503 & 0,449 & 0,548 \\
\hline Fabricação de produtos de minerais não-metálicos & 0,266 & 0,241 & 0,438 & 0,392 & 0,311 & 0,389 \\
\hline Metalurgia básica & 0,585 & 0,556 & 0,648 & 0,584 & 0,508 & 0,631 \\
\hline Fabric. de produtos de metal - exclusive máq. e equip. & 0,558 & 0,430 & 0,521 & 0,492 & 0,409 & 0,508 \\
\hline Fabricação de máquinas e equipamentos & 0,656 & 0,539 & 0,646 & 0,616 & 0,539 & 0,633 \\
\hline Fabric. de máq. para escritório e equip. de informática & 0,581 & 0,651 & 0,813 & 0,816 & 0,902 & 0,788 \\
\hline Fabric. de máquinas, aparelhos e materiais elétricos & 0,603 & 0,592 & 0,641 & 0,595 & 0,518 & 0,628 \\
\hline Fabricação de mat. eletrôn. e equip.de comunicação & 0,667 & 0,701 & 0,711 & 0,690 & 0,718 & 0,695 \\
\hline Fabric. de equipamentos de instrum. médico-hospitalar & 0,654 & 0,578 & 0,685 & 0,669 & 0,615 & 0,677 \\
\hline Fabric. e montagem de veículos automotores & 0,614 & 0,626 & 0,682 & 0,658 & 0,547 & 0,675 \\
\hline Fabricação de outros equipamentos de transporte & 0,703 & 0,417 & 0,743 & 0,623 & 0,526 & 0,718 \\
\hline Fabricação de móveis e indústrias diversas & 0,470 & 0,334 & 0,437 & 0,381 & 0,348 & 0,408 \\
\hline Reciclagem & 0,315 & 0,336 & 0,388 & 0,362 & 0,317 & 0,370 \\
\hline Total & 0,493 & 0,376 & 0,580 & 0,473 & 0,423 & 0,522 \\
\hline
\end{tabular}

Fonte: Índices calculados a partir dos dados da Rais 2005

Nota: Os índices foram obtidos pelo método baseado no IDH. 


\section{ANÁlISE MULTIVARIADA - ÍNDICES E GRUPOS DE SETORES}

Esta seção está dividida em duas partes. Inicialmente, é apresentada a metodologia e são calculados índices setoriais e regionais a partir da análise de componentes principais (ACP). Em seguida, os setores são agrupados pela técnica de análise de grupamento.

\subsection{Cálculo dos índices}

Seja um conjunto de $n$ objetos $\mathrm{O}_{1}, \ldots \ldots . . ., \mathrm{O}_{\mathrm{n}}$ que se deseja ordenar, segundo um conjunto de $p$ variáveis $X_{1}, \ldots \ldots ., X_{p}$.

A cada objeto $\mathrm{O}_{\mathrm{i}}$, associamos um valor

$$
I_{i}=p_{1} X_{i 1}+p_{2} X_{\mathrm{i} 2}+\ldots \ldots+p_{p} X_{i p}
$$

onde: $X_{i 1}, X_{i 2}, \ldots ., X_{i p}$ são os valores das variáveis observadas para $\mathrm{O}_{\mathrm{i}}$

$p_{1}, p_{2}, \ldots ., p_{p} \quad$ são os pesos das variáveis.

Os pesos escolhidos devem traduzir a importância de cada variável, isto é, às variáveis mais importantes na ordenação devem ser atribuídos os maiores pesos. Uma medida de importância estatística de uma variável pode ser dada pela variância, que mede a quantidade de informação contida na variável. Assim podemos estabelecer a ligação entre importância e variância. Sendo a ACP uma técnica que fornece a primeira componente com variância máxima, usaremos essa componente $\left(\mathrm{C}_{1}\right)$ como índice.

$$
I_{i}=a_{1} X_{i 1}+a_{2} X_{\mathrm{i} 2}+\ldots \ldots . .+a_{p} X_{i p}
$$

onde $i=1, \ldots n$, referem-se aos objetos que serão ordenados.

Assim, os pesos de cada variável serão os coeficientes que definem a primeira componente principal.

A utilização da ACP na construção do índice garante que:

- pesos maiores estarão associados às variáveis que contribuem mais para a variância do conjunto dos dados;

- o índice resultante será padronizado: média zero, desvio padrão unitário.

Portanto, na leitura dos resultados, divisões da indústria com desempenhos "médios" receberão valores em torno de "0" para o índice, enquanto as melhores receberão os valores mais altos (positivos) e as piores receberão os valores mais baixos (negativos).

A partir da análise de componentes principais, foram criados índices para as 27 divisões industriais no conjunto do País e nas cinco regiões naturais no ano de 2005 . $^{15}$ Os índices foram calculados de tal forma que permitem uma ordenação das divisões segundo os valores das três va-

15 Um exemplo de aplicação desta técnica para construção de índices pode ser vista em Kubrusly (2001). 
riáveis utilizadas na Seção 3 - remuneração, escolaridade e porcentual de trabalhadores técnicos e científicos.

O índice resultante é uma média ponderada das três variáveis. Diferentemente da seção anterior, em que os pesos foram arbitrados, os pesos aqui são determinados pela análise de componentes principais. Quanto maior o valor do índice, maior tende a ser o nível de remuneração e de escolaridade dos trabalhadores e o porcentual de trabalhadores técnicos e científicos da respectiva divisão. ${ }^{16}$

Os resultados, para o conjunto do País no período, mostram que o maior índice é encontrado na extração de petróleo, certamente influenciado pelas excelentes condições de trabalho encontradas na Petrobras. Ele supera o valor 3, diferenciando-se dos demais setores, e sendo quase o dobro do segundo maior índice, encontrado na fabricação de máquinas para escritório e equipamentos de informática. Com valores relativamente elevados, podem ainda ser mencionados os setores de extração de metais metálicos, fabricação de outros equipamentos de transporte, fabricação de material eletrônico e aparelhos de comunicação e fabricação de produtos químicos. Portanto, ou são setores extrativos dominados por grandes empresas nacionais como a Petrobras e a Vale do Rio Doce, ou da indústria de transformação nas áreas de informática, eletrônica e química, com forte presença de multinacionais estrangeiras, ou ainda da Embraer na área de equipamentos de transporte.

Em seguida, há um continuum de valores para o índice, com destaque para alguns setores mais dinâmicos e modernos da indústria de transformação, como fabricação de veículos automotores, produtos de fumo, edição e impressão, etc.

Os piores resultados foram encontrados em setores tradicionais, conhecidos por apresentarem menores níveis de produtividade e oferecerem piores condições de trabalho, como fabricação de alimentos e bebidas, de móveis, de produtos minerais não-metálicos, confecção de vestuário, fabricação de artigos de couro e calçados, de produtos de madeira e reciclagem, entre outros. Em todos os casos mencionados, o índice nacional apresenta valores negativos, chegando a -1,358 na fabricação de produtos de madeira.

A comparação dos resultados acima com aqueles desenvolvidos na Seção 3 mostra que, apesar das diferenças metodológicas, a ordenação dos índices nas 27 divisões é bastante semelhante nos dois casos (Tabela 6). Em outras palavras, as divisões que se destacam, tanto positiva, quanto negativamente, são as mesmas. Isto fica ainda confirmado pelo coeficiente de correlação de ordem que atingiu 0,990 , enquanto o coeficiente de correlação entre os valores dos índices foi de $0,967 .^{17}$

16 A primeira componente da ACP utilizada para o índice capta cerca de $85 \%$ da variância total dos dados.

17 Tal resultado não chega a surpreender, na medida em que os pesos estimados para os índices desta seção são muito próximos aos pesos arbitrários (iguais a 0,333) utilizados nos índices da Seção 3. Exemplificando, os pesos utilizados no índice nacional foram, respectivamente, $0,343,0,358$ e 0,382 . 
Tabela 6 - Ordenação dos dois índices por divisão para o Brasil - 2005

\begin{tabular}{|c|c|c|c|c|}
\hline Divisão & Índice 1 & Ordenação & Índice 2 & Ordenação \\
\hline Extração de petróleo e serviços relacionados & 0,922 & 1 & 3,074 & 1 \\
\hline Fabric. de máq. para escritório e equip. de informática & 0,788 & 2 & 1,568 & 2 \\
\hline Extração de minerais metálicos & 0,720 & 3 & 0,931 & 3 \\
\hline Fabricação de outros equipamentos de transporte & 0,718 & 4 & 0,845 & 4 \\
\hline Fabricação de produtos químicos & 0,711 & 5 & 0,761 & 5 \\
\hline Fabric. de mat. eletrôn. e equip.de comunicação & 0,695 & 6 & 0,752 & 6 \\
\hline Fabric. de equipamentos de instrum. médico-hospitalar & 0,677 & 8 & 0,633 & 7 \\
\hline Fabricação de produtos do fumo & 0,685 & 7 & 0,598 & 8 \\
\hline Fabric. e montagem de veículos automotores & 0,675 & 9 & 0,452 & 9 \\
\hline Edição, impressão e reprodução de gravações & 0,650 & 10 & 0,389 & 10 \\
\hline Fabricação de máquinas e equipamentos & 0,633 & 11 & 0,224 & 11 \\
\hline Fabricação de máquinas, aparelhos e materiais elétricos & 0,628 & 13 & 0,205 & 12 \\
\hline Metalurgia básica & 0,631 & 12 & 0,201 & 13 \\
\hline Refino de petróleo e álcool & 0,587 & 14 & $-0,072$ & 14 \\
\hline Fabricação de celulose, papel e produtos de papel & 0,583 & 15 & $-0,099$ & 15 \\
\hline Fabricação de artigos de borracha e plástico & 0,548 & 16 & $-0,243$ & 16 \\
\hline Fabric. de produtos de metal - exclusive máq. e equip. & 0,508 & 17 & $-0,468$ & 17 \\
\hline Fabricação de produtos têxteis & 0,446 & 19 & $-0,722$ & 18 \\
\hline Extração de carvão mineral & 0,454 & 18 & $-0,757$ & 19 \\
\hline Fabricação de móveis e indústrias diversas & 0,408 & 20 & $-0,813$ & 20 \\
\hline Confecção de artigos do vestuário e acessórios & 0,355 & 25 & $-0,924$ & 21 \\
\hline Fabricação de produtos alimentícios e bebidas & 0,408 & 21 & $-0,930$ & 22 \\
\hline Reciclagem & 0,370 & 23 & $-1,013$ & 23 \\
\hline Fabricação de produtos de minerais não-metálicos & 0,389 & 22 & $-1,015$ & 24 \\
\hline Fabric. de artefatos de couro e calçados & 0,319 & 26 & $-1,103$ & 25 \\
\hline Extração de minerais não-metálicos & 0,369 & 24 & $-1,113$ & 26 \\
\hline Fabricação de produtos de madeira & 0,273 & 27 & $-1,358$ & 27 \\
\hline
\end{tabular}

A análise por região tende a confirmar os resultados nacionais, como no caso da região Sudeste. ${ }^{18}$ Nas cinco regiões, os coeficientes de correlação entre os resultados dos dois índices são elevados, sistematicamente acima de 0,9. Há, entretanto, algumas características regionais que merecem ser explicitadas.

18 Cabe mencionar que a os índices regionais são obtidos separadamente, de modo que os pesos aplicados às variáveis são distintos segundo a região considerada. Apenas para exemplificar, no caso da região Nordeste, os pesos são, respectivamente, 0,349, 0,405, 0,426. Portanto, os resultados dos índices obtidos nas várias regiões não são estritamente comparáveis. 
Na região Norte, por exemplo, o setor de extração de petróleo é um verdadeiro outlier, sendo seu índice cinco vezes maior que o segundo mais elevado encontrado na extração de minerais metálicos. Por outro lado, todos os segmentos típicos da Zona Franca de Manaus, como fabricação de material eletrônico e aparelhos de comunicação, de máquinas para escritório, de equipamentos de informática e de outros equipamentos de transporte, possuem índices positivos, confirmando os resultados da Seção 3.

A região Centro-Oeste, por outro lado, é a única em que a extração de petróleo não possui o melhor índice. Cabe, entretanto, observar que este segmento é praticamente inexistente localmente. O índice mais alto é encontrado na fabricação de máquinas para escritório e equipamentos de informática, seguindo-se a fabricação de material eletrônico e equipamentos de comunicação. Nos dois casos, representam segmentos onde a indústria é inexpressiva na região.

A Tabela 7 ilustra os valores dos índices das 27 divisões nas cinco regiões em 2005.

\section{Tabela 7 - Índices de desenvolvimento da indústrias de transformação e extrativa mineral por} divisão - 2005

\begin{tabular}{|c|c|c|c|c|c|c|}
\hline Divisão & $\mathbf{N}$ & NE & SE & $\mathbf{S}$ & $\mathrm{CO}$ & Brasil \\
\hline Extração de petróleo e serviços relacionados & 3,934 & 2,859 & 2,880 & 2,934 & 0,753 & 3,074 \\
\hline Fabric. de máq. para escritório e equip. de informática & 0,165 & 1,060 & 1,581 & 2,116 & 3,483 & 1,568 \\
\hline Extração de minerais metálicos & 0,808 & 0,766 & 0,969 & $-0,879$ & 0,636 & 0,931 \\
\hline Fabricação de outros equipamentos de transporte & 0,698 & $-0,335$ & 0,832 & 0,400 & 0,044 & 0,845 \\
\hline Fabricação de produtos químicos & $-0,630$ & 0,897 & 0,788 & 0,690 & 0,311 & 0,761 \\
\hline Fabric. de mat. eletrôn. e equip.de comunicação & 0,571 & 1,912 & 0,601 & 0,933 & 1,737 & 0,752 \\
\hline Fabric. de equipamentos de instrum. médico-hospitalar & 0,585 & 0,620 & 0,483 & 0,753 & 0,702 & 0,633 \\
\hline Fabricação de produtos do fumo & 0,105 & $-0,703$ & 0,807 & 1,176 & 0,856 & 0,598 \\
\hline Fabric. e montagem de veículos automotores & 0,244 & 0,656 & 0,323 & 0,631 & 0,179 & 0,452 \\
\hline Edição, impressão e reprodução de gravações & 0,399 & 0,725 & 0,320 & 0,273 & 0,732 & 0,389 \\
\hline Fabricação de máquinas e equipamentos & 0,503 & 0,183 & 0,123 & 0,347 & 0,117 & 0,224 \\
\hline Fabricação de máquinas, aparelhos e materiais elétricos & 0,238 & 0,508 & 0,110 & 0,203 & 0,050 & 0,205 \\
\hline Metalurgia básica & 0,044 & 0,253 & 0,108 & 0,142 & $-0,095$ & 0,201 \\
\hline Refino de petróleo e álcool & $-0,361$ & $-0,601$ & 0,917 & $-0,437$ & $-0,837$ & $-0,072$ \\
\hline Fabricação de celulose, papel e produtos de papel & $-0,015$ & 0,169 & $-0,031$ & $-0,247$ & $-0,121$ & $-0,099$ \\
\hline Fabricação de artigos de borracha e plástico & 0,490 & 0,175 & $-0,325$ & $-0,316$ & $-0,312$ & $-0,243$ \\
\hline Fabric. de produtos de metal - exclusive máq. e equip. & $-0,021$ & $-0,342$ & $-0,534$ & $-0,376$ & $-0,473$ & $-0,468$ \\
\hline Fabricação de produtos têxteis & $-0,649$ & $-0,418$ & $-0,801$ & $-0,537$ & $-0,461$ & $-0,722$ \\
\hline Extração de carvão mineral & $-1,369$ & $-1,577$ & $-1,336$ & $-0,388$ & $-1,353$ & $-0,757$ \\
\hline Fabricação de móveis e indústrias diversas & $-0,367$ & $-0,645$ & $-0,815$ & $-0,777$ & $-0,671$ & $-0,813$ \\
\hline Confecção de artigos do vestuário e acessórios & $-0,685$ & $-0,692$ & $-0,989$ & $-0,816$ & $-0,682$ & $-0,924$ \\
\hline Fabricação de produtos alimentícios e bebidas & $-0,646$ & $-1,180$ & $-0,723$ & $-0,675$ & $-0,543$ & $-0,930$ \\
\hline Reciclagem & $-0,771$ & $-0,669$ & $-1,046$ & $-0,967$ & $-0,828$ & $-1,013$ \\
\hline Fabricação de produtos de minerais não-metálicos & $-0,976$ & $-1,079$ & $-0,920$ & $-0,828$ & $-0,906$ & $-1,015$ \\
\hline Fabric. de artefatos de couro e calçados & $-0,950$ & $-0,663$ & $-1,041$ & $-1,130$ & $-0,710$ & $-1,103$ \\
\hline Extração de minerais não-metálicos & $-0,074$ & $-0,798$ & $-1,222$ & $-1,064$ & $-0,373$ & $-1,113$ \\
\hline Fabricação de produtos de madeira & $-1,271$ & $-1,082$ & $-1,060$ & $-1,160$ & $-1,235$ & $-1,358$ \\
\hline
\end{tabular}

Fonte: Índices calculados a partir dos dados da Rais 2005.

Nota: Os índices foram obtidos pela análise de componentes principais. 
Observando os resultados das Tabelas 5 e 7, vemos que alguns valores dos índices, em alguns setores, apontam para marcantes diferenças regionais. Assim, a extração de minerais metálicos apresenta uma posição muito baixa na região Sul, ao contrário das demais regiões. Voltando aos dados das Tabelas 1 a 4, vemos que esse setor possui remuneração abaixo da média na região, escolaridade muito abaixo da média e porcentual de trabalhadores técnicos e científicos também muito abaixo da média, ao contrário do que ocorre nas demais regiões. No que se refere ao número de empregos, pode-se afirmar que esse setor não é importante na região Sul.

O setor de refino de petróleo e álcool destaca-se muito na região Sudeste, devido principalmente à alta remuneração (muito acima da média na região) e alta concentração de trabalhadores técnicos e científicos (mais do dobro da média regional). Não deve ser esquecido que esse setor é muito heterogêneo, incluindo grandes refinarias de petróleo da Petrobras no Sudeste e engenhos de produção de álcool no interior do Nordeste. Daí sua forte desigualdade regional.

A fabricação de produtos do fumo apresenta nítida polarização Nordeste x Sul, explicada, em primeiro lugar, pela remuneração que, para esse setor, apresenta valor muito acima da média na região Sul e abaixo da média na região Nordeste. Em segundo lugar, a participação de profissionais técnicos e científicos no setor apresenta-se acima da média da indústria nas duas regiões, porém, na região Nordeste, cerca de $30 \%$ acima da média, enquanto que, na região Sul, a participação desse setor é quase três vezes a média regional.

O setor de fabricação de outros equipamentos de transporte também apresenta diferenças marcantes na sua posição para as regiões Nordeste e Sudeste. Trata-se de setor avançado na região Sudeste, que inclui, por exemplo, a Embraer, apresentando valores para remuneração e participação de trabalhadores técnicos e científicos quase $100 \%$ maior que a média regional, enquanto que, na região Nordeste, o mau desempenho do setor deve-se às mesmas variáveis, as quais apresentam valores abaixo da média regional.

Em resumo, os resultados obtidos com os índices desta seção confirmam aqueles da seção anterior, fortalecendo as conclusões já apresentadas relativamente aos diferenciais no nível de desenvolvimento da indústria brasileira, segundo as regiões e setores considerados.

\subsection{Grupos de setores}

Após o cálculo dos índices obtidos na seção anterior, as divisões da indústria foram agregadas por meio da técnica de análise de grupamento. Foram utilizados os dados setoriais das três variáveis no conjunto do País. Foram identificados três grupos de setores, além de um quarto formado apenas pela extração de petróleo (Figura 1).

O primeiro grupo possui oito divisões, cujos índices são todos positivos. Ele é composto por segmentos diversos de produtos eletrônicos, material de transporte, edição e impressão, produtos químicos, fumo, além da extração de minerais metálicos. São setores dominados por grandes empresas nacionais ou multinacionais. Podemos acrescentar a extração de petróleo, obtendo-se um grupo semelhante àquele identificado por Kupfer e Rocha (2004) com alta produtividade e altas taxas de crescimento da produtividade no passado recente. 


\section{Figura 1 - Análise de grupamento das divisões da indústria - Brasil - 2005}

\section{Índice - Divisão na Indústria}

\section{3,07 Extração de petróleo e serv.}

0,75 Mat. eletrôn. equip. comun.

0,63 Instrum. médicohospitalar

0,39 Edição, impressão

0,76 Produtos químicos

0,84 Outros equip. transporte

0,60 Produtos do fumo

0,93 Extr. minerais metálicos

1,57 Maq. escrit. equip. inform.

$-0,10$ Celulose e papel

-0,24 Artigos de borracha

$-0,47$ Prod. met. (excl. maq. equip.)

0,22 Máquinas e equipamentos

0,21 Maq. materiais elétricos

0,20 Metalurgia básica

0,45 Veículos automotores

-0,07 Refino de petróleo e álcool

-0,93 Prod. aliment. e bebidas

$-1,01$ Prod. minerais não-metálicos

$-1,10$ Calçados e artefatos de couro

$-1,01$ Reciclagem

-0,76 Extr. carvão mineral

-1,11 Extr. min. não-metálicos

$-1,34$ Produtos de madeira

$-0,92$ Artigos do vestuário

$-0,81$ Móveis e ind. diversas

$-0,72$ Produtos têxteis
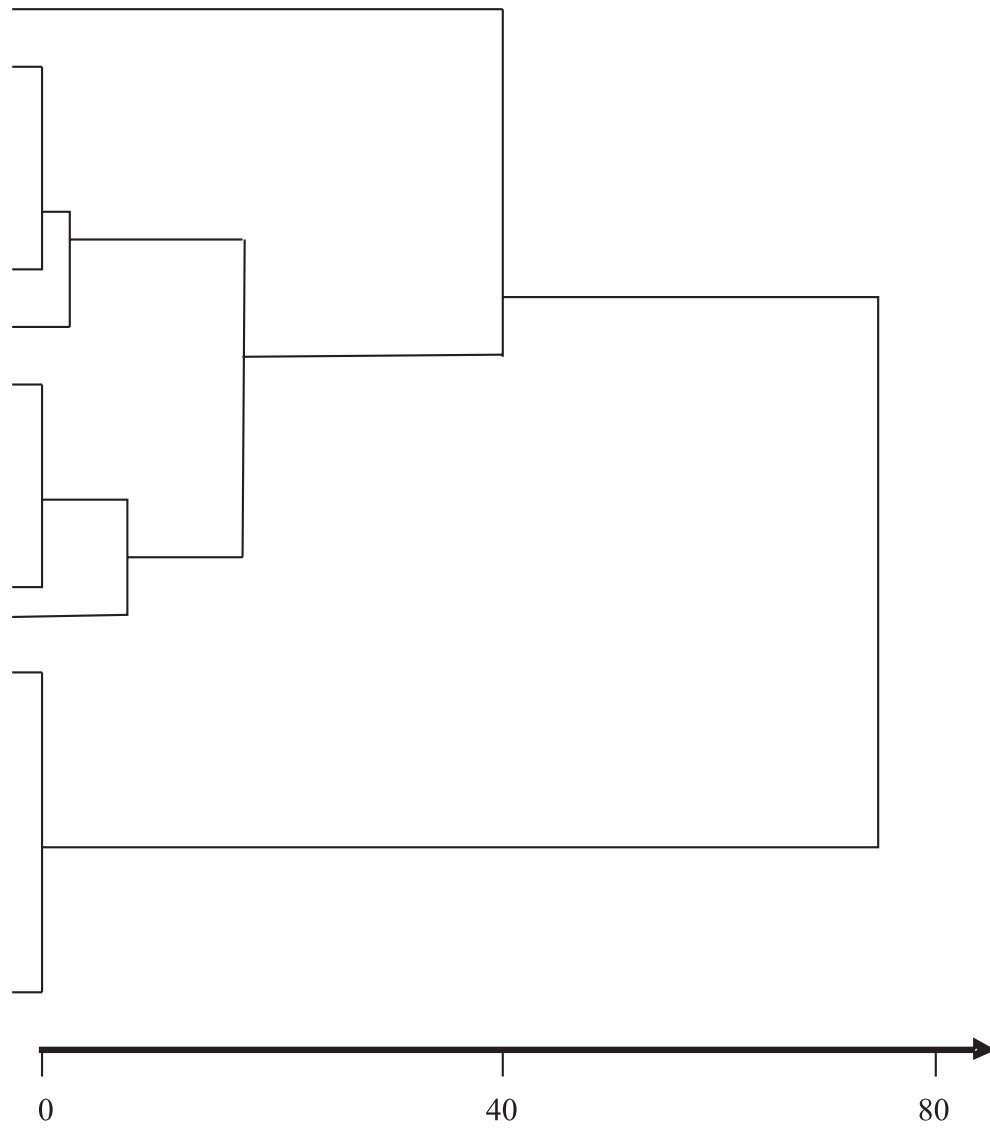

O segundo grupo é composto por oito divisões com características variadas e valores intermediários para os índices. São elas: fabricação de veículos automotores; fabricação de máquinas, aparelhos e equipamentos elétricos; fabricação de máquinas e equipamentos em geral; de papel e celulose; de artigos de borracha; metalurgia básica; refino de petróleo, e produção de álcool. ${ }^{19}$ Os índices variam em torno do valor zero. ${ }^{20} \mathrm{Em}$ geral, são setores industriais com alta produtividade, porém com taxas de crescimento da produtividade menores que o primeiro grupo. ${ }^{21}$

O terceiro grupo inclui as dez divisões restantes com os piores índices. A regra geral é encontrar valores negativos para os índices dessas divisões. São segmentos representativos da indústria tradicional, incluindo setores extrativos como de carvão mineral e de minerais não-metálicos; bens de consumo não duráveis como alimentos e bebidas, vestuário, calçados, etc., e bens intermediários como têxtil, madeira e reciclagem. Em geral, tais setores são caracterizados por menores taxas de

19 Pode parecer estranho o refino de petróleo não fazer parte do melhor grupo. Isso pode ser explicado facilmente pelo fato de estar incluído numa divisão muito heterogênea, onde o refino de petróleo e a fabricação de combustíveis nucleares possuem condições bem mais favoráveis do que a encontrada nas coquerias e na produção de álcool.

20 Cabe lembrar que os índices foram construídos de modo que sua média é nula.

21 Ver Kupfer e Rocha op. cit.. 
produtividade que os demais, embora alguns tenham experimentado grande crescimento nos últimos anos. 22

\subsection{Heterogeneidade regional}

Os resultados da análise de grupamento juntamente com os índices obtidos nas diversas regiões permitem que seja feito um cruzamento entre os dados de modo a classificar as 27 divisões industriais segundo seu nível de desenvolvimento e seu grau de heterogeneidade entre as diversas regiões.

O agrupamento dos setores utilizado nesta seção é exatamente aquele da Seção 4.2 com duas modificações. Em primeiro lugar, a extração de petróleo é agrupada com as divisões do primeiro grupo que têm os melhores índices. Em segundo lugar, a fabricação de veículos automotores também é incorporada ao primeiro grupo, tendo em vista seus índices mais elevados que os demais pertencentes ao segundo grupo. Assim, o primeiro grupo fica com as dez "melhores" divisões.

O segundo grupo é composto pelas divisões formadas na análise de grupamento com índices intermediários, retirando-se a fabricação de veículos automotores deslocada para o primeiro grupo. Tal grupo possui 7 divisões.

Finalmente, o terceiro grupo é formado pelas dez divisões restantes, representando a indústria tradicional com os "piores" resultados.

Para se medir o nível de heterogeneidade regional das 27 divisões, foram considerados os índices regionais de cada divisão obtidos na Seção 3 e calculada a relação entre o maior e o menor índice regional. ${ }^{23}$ De maneira simplificada, poderiam ser consideradas homogêneas as divisões com relações até 1,5 e heterogêneas aquelas com relações acima de 1,5. Assim, foram obtidas 15 divisões homogêneas e 12 heterogêneas.

Não há uma relação clara entre o nível de desenvolvimento das divisões e seu grau de heterogeneidade regional. No primeiro grupo, por exemplo, são encontradas duas divisões com os menores níveis de heterogeneidade - fabricação de material eletrônico e de aparelhos e equipamentos de comunicação e fabricação de equipamentos de instrumentação para uso médico-hospitalalar. Por outro lado, são encontradas divisões com alto grau de heterogeneidade regional, como produtos químicos, produtos de fumo, outros equipamentos de transporte e extração de minerais metálicos.

No terceiro grupo, onde são encontradas as divisões com os menores níveis de desenvolvimento, há segmentos relativamente homogêneos, como couro, calçados, vestuários, têxteis e reciclagem, ao lado de segmentos heterogêneos como extração de carvão mineral, produtos de madeira, produtos de minerais não-metálicos e produtos alimentícios e bebidas.

O segundo grupo é o único a apresentar um padrão uniforme com divisões industriais relativamente homogêneas. Somente a divisão de refino de petróleo e produção de álcool apresenta alto

22 Ver Kupfer e Rocha op. cit..

23 Como os índices regionais da Seção 4 não são estritamente comparáveis entre si, foram utilizados os índices da Seção 3 para o cálculo do nível de heterogeneidade. 
grau de heterogeneidade regional por razões óbvias, ao incorporar segmentos modernos como o refino de petróleo e tradicionais como a produção de álcool.

O Quadro 1 apresenta as 27 divisões distribuídas segundo seu nível de desenvolvimento e grau de heterogeneidade regional.

\section{Quadro 1 - Nível de Desenvolvimento e Grau de Heterogeneidade Regional das Divisões da Indústria - 2005}

\begin{tabular}{|c|c|c|}
\hline \multirow{2}{*}{$\begin{array}{c}\text { Nível de } \\
\text { Desenvolvimento }\end{array}$} & \multicolumn{2}{|c|}{ Grau de Heterogeneidade } \\
\hline & Baixo & Alto \\
\hline Baixo & $\begin{array}{l}\text { Calçados e artefatos de couro } \\
\text { Reciclagem } \\
\text { Artigos de vestuário } \\
\text { Móveis e ind. diversas } \\
\text { Produtos têxteis }\end{array}$ & $\begin{array}{c}\text { Prod. alimentares e bebidas } \\
\text { Prod. minerais não metálicos } \\
\text { Extração de carvão mineral } \\
\text { Extração de minerais não-metálicos } \\
\text { Produção de madeira }\end{array}$ \\
\hline Médio & $\begin{array}{c}\text { Celulose e papel } \\
\text { Artigos de borracha } \\
\text { Prod. metal (exceto maq. equip.) } \\
\text { Máquinas e equipamentos } \\
\text { Máquinas e materiais elétricos } \\
\text { Metalurgia básica }\end{array}$ & Refino de petróleo e álcool \\
\hline Alto & $\begin{array}{l}\text { Veículos automotores } \\
\text { Material eletrônico e equip. comun. } \\
\text { Instrum. médico-hospitalar } \\
\text { Edição e impressão }\end{array}$ & $\begin{array}{c}\text { Extração de petróleo } \\
\text { Produtos químicos } \\
\text { Outros equip. transporte } \\
\text { Produtos de fumo } \\
\text { Extração de minerais metálicos } \\
\text { Mat. escrit. e equip. informática }\end{array}$ \\
\hline
\end{tabular}

Os resultados encontrados confirmam a existência de heterogeneidade regional no interior da indústria brasileira, embora não permita que se determine uma clara relação com o nível de desenvolvimento de cada setor da indústria. Em parte, esse resultado se deve à classificação da indústria em divisões, que não é a forma ideal para medir o grau de heterogeneidade regional, na medida em que diferentes segmentos industriais podem fazer parte de uma mesma divisão, sendo casos típicos, por exemplo, refino de petróleo e álcool e outros equipamentos de transporte, já mencionados anteriormente. Se uma região se especializa no refino de petróleo, enquanto outra na produção de álcool, inevitavelmente haverá uma grande heterogeneidade entre as regiões. Uma análise alternativa para o grau de heterogeneidade setorial/regional seria por meio da desagregação da indústria em grupos em vez de divisões, na medida em que os primeiros seriam, em princípio, mais homogêneos. ${ }^{24}$ 


\subsection{Níveis de produtividade regional e setorial}

Conforme destacado na introdução do artigo, as três variáveis utilizadas no cálculo dos índices não são variáveis de "resultados" das empresas, o que poderia levantar dúvidas sobre a qualidade dos indicadores para medir o efetivo nível de desenvolvimento da indústria. ${ }^{25}$ Portanto, seria desejável verificar até que ponto tais índices seriam coerentes com outras variáveis que medem a performance efetiva da indústria.

Com esse objetivo, foram calculadas as produtividades das 27 divisões nas cinco regiões, a partir dos dados de 2005 da Pesquisa Industrial Anual (PIA) do IBGE. Utilizou-se como medida da produtividade a divisão do valor da transformação industrial (VTI) pelo pessoal ocupado (PO). A Tabela 8 apresenta os dados de produtividade calculados. Alguns resultados merecem ser destacados.

Em primeiro lugar, o fato de a região Norte possuir o maior nível de produtividade, superando a região Sudeste. Tal fato, até certo ponto surpreendente, se repete em 14 das 27 divisões da indústria.

Em segundo lugar, a confirmação de fortes diferenciais de produtividade entre os setores e regiões, reafirmando a heterogeneidade setorial/regional encontrada com os índices desenvolvidos ao longo do texto.

$\mathrm{Na}$ indústria extrativa mineral, os maiores níveis de produtividade são encontrados na extração de petróleo e na extração de minerais metálicos, que correspondem a duas divisões já destacadas entre os maiores índices encontrados com as duas metodologias utilizadas.

Na indústria de transformação, as produtividades mais elevadas cabem ao refino de petróleo e produção de álcool, metalurgia básica, fabricação de produtos químicos e fabricação de produtos do fumo. As menores, às divisões da indústria tradicional, como vestuário, têxtil, couro, madeira, móveis, entre outras.

Para verificar a correspondência entre os índices baseados nas duas metodologias e os indicadores de produtividade, foram calculados os coeficientes de correlação de ordem no Brasil e nas cinco regiões. Os resultados estão apresentados na Tabela 9.

Conforme pode ser verificado, em geral os coeficientes de correlação são significativos, positivos e elevados. Para o conjunto do País, os valores encontrados foram 0,777, no caso dos índices baseados na análise de componentes principais, e 0,822 , quando considerada a metodologia do IDH.

Em quatro das cinco regiões, as correlações foram altas e positivas. No caso do Sudeste, por exemplo, os valores foram, respectivamente, 0,799 e 0,836. A única exceção é a região Centro-Oeste, onde as correlações encontradas não são significativamente diferentes de zero. ${ }^{26}$

Os dados discutidos nesta seção fortalecem os resultados dos índices desenvolvidos no artigo utilizando as duas metodologias, mostrando sua capacidade para diferenciar e ordenar a indústria brasileira segundo seu nível de desenvolvimento setorial e regional.

25 Ver nota de rodapé 8.

26 Com exceção do Centro-Oeste, todas as correlações apresentadas na Tabela 9 são significativas ao nível de $1 \%$. 
Tabela 8 - Índices de produtividade industrial por divisão e região natural - 2005

\begin{tabular}{|c|c|c|c|c|c|c|}
\hline Divisão & $\mathbf{N}$ & $\mathrm{NE}$ & SE & $S$ & $\mathrm{CO}$ & Brasil \\
\hline Extração de carvão mineral & - & - & - & 53.013 & - & 68.219 \\
\hline Extração de petróleo e serviços relacionados & 2.287 .155 & 402.508 & 667.863 & 2.921 .789 & - & 626.699 \\
\hline Extração de minerais metálicos & 826.852 & 227.831 & 554.471 & 12.040 & 124.024 & 482.475 \\
\hline Extração de minerais não-metálicos & 16.686 & 67.328 & 34.788 & 44.786 & 88.009 & 43.045 \\
\hline Fabricação de produtos alimentícios e bebidas & 106.161 & 30.745 & 73.502 & 58.131 & 91.826 & 63.778 \\
\hline Fabricação de produtos do fumo & 59.767 & 11.595 & 101.437 & 316.552 & 11.721 & 146.914 \\
\hline Fabricação de produtos têxteis & 20.227 & 31.958 & 33.970 & 36.921 & 33.948 & 34.214 \\
\hline Confecção de artigos do vestuário e acessórios & 7.835 & 11.441 & 13.877 & 17.036 & 15.615 & 14.529 \\
\hline Fabric. de artefatos de couro e calçados & 59.491 & 25.880 & 16.565 & 21.396 & 30.940 & 21.483 \\
\hline Fabricação de produtos de madeira & 25.819 & 18.410 & 34.420 & 31.704 & 27.489 & 30.267 \\
\hline Fabricação de celulose, papel e produtos de papel & 136.873 & 113.223 & 122.474 & 83.838 & 59.979 & 109.988 \\
\hline Edição, impressão e reprodução de gravações & 139.435 & 34.063 & 88.463 & 44.612 & 40.030 & 74.516 \\
\hline Refino de petróleo e álcool & - & 338.655 & 809.758 & 977.828 & 71.841 & 623.737 \\
\hline Fabricação de produtos químicos & 123.994 & 240.529 & 145.648 & 177.068 & 75.917 & 154.999 \\
\hline Fabricação de artigos de borracha e plástico & 58.621 & 43.139 & 58.877 & 44.580 & 22.815 & 53.391 \\
\hline Fabricação de produtos de minerais não-metálicos & 46.941 & 35.685 & 54.222 & 49.060 & 39.669 & 49.223 \\
\hline Metalurgia básica & 262.637 & 205.815 & 225.178 & 107.595 & 153.458 & 208.769 \\
\hline Fabric. de produtos de metal - exclusive máq. e equip. & 128.849 & 55.918 & 51.739 & 40.285 & 46.947 & 50.513 \\
\hline Fabricação de maquinas e equipamentos & 149.173 & 40.487 & 67.670 & 66.953 & 39.112 & 66.356 \\
\hline Fabric. de máq. para escritório e equip. de informática & 123.972 & 349.355 & 64.310 & 110.015 & 17.238 & 98.760 \\
\hline Fabricação de máquinas, aparelhos e materiais elétricos & 58.625 & 67.889 & 63.701 & 61.016 & 31.341 & 62.901 \\
\hline Fabric. de mat. eletrôn. e equip.de comunicação & 170.931 & 71.892 & 108.040 & 126.626 & 8.463 & 130.641 \\
\hline Fabric. de equipamentos de instrum. médico-hospitalar & 157.287 & 39.191 & 61.031 & 58.481 & 27.718 & 63.069 \\
\hline Fabric. e montagem de veículos automotores & 58.837 & 173.542 & 112.687 & 88.601 & 97.176 & 108.289 \\
\hline Fabricação de outros equipamentos de transporte & 168.910 & 49.922 & 93.914 & 47.325 & 26.910 & 97.654 \\
\hline Fabricação de móveis e indústrias diversas & 64.225 & 15.659 & 25.038 & 30.294 & 14.392 & 26.600 \\
\hline Reciclagem & 18.140 & 20.355 & 40.563 & 28.146 & 22.986 & 33.142 \\
\hline TOTAL & 130.792 & 60.330 & 93.894 & 56.315 & 65.285 & 80.289 \\
\hline
\end{tabular}

Fonte: Índices calculados a partir da PIA 2005.

Nota: VTI/PO (em reais por pessoa ocupada).

Tabela 9 - Correlação de ordem entre os índices de produtividade e de desenvolvimento (IDH e ACP)

\begin{tabular}{ccccccc}
\hline & $\mathbf{N}$ & $\mathrm{NE}$ & $\mathrm{SE}$ & $\mathbf{S}$ & $\mathrm{CO}$ & Brasil \\
\hline Índice IDH & 0,746 & 0,746 & 0,836 & 0,787 & 0,038 & $\mathbf{0 , 8 2 2}$ \\
Índice ACP & 0,730 & 0,711 & 0,799 & 0,770 & $-0,057$ & $\mathbf{0 , 7 7 7}$ \\
\hline
\end{tabular}




\section{CONCLUSÕES}

Nesta seção são apresentadas as principais conclusões do trabalho. Em alguns casos, os resultados encontrados seguem a linha do que seria esperado. Em outros, há algumas surpresas.

O primeiro ponto a ser destacado é a própria metodologia utilizada, na qual foram comparados resultados obtidos a partir de indicadores simples e intuitivos com outros desenvolvidos a partir de técnicas estatísticas multivariadas. A semelhança entre os resultados encontrados aponta no sentido de que a boa intuição pode conduzir a resultados corretos.

Com relação aos resultados empíricos, verificou-se que a indústria continua apresentando forte heterogeneidade regional. Os dados confirmam a superioridade da indústria na região Sudeste relativamente ao restante do País. A região Norte foi a principal surpresa, mostrando índices de desenvolvimento da indústria comparáveis aos encontrados na região Sul. Os resultados no Nordeste e Centro-Oeste são os mais desfavoráveis.

Também em termos setoriais, as diferenças são marcantes. Há um continuum de indicadores, desde os mais favoráveis, encontrados na extração de petróleo, até os obtidos em segmentos da indústria tradicional como na fabricação de produtos de madeira, preparação de couro, reciclagem, etc.

A análise multivariada conseguiu agregar os setores da indústria de transformação e extrativa mineral em três grandes grupos. O primeiro, com os melhores indicadores, possui segmentos extrativos, da eletroeletrônica, de material de transporte, produtos químicos, fumo, edição e impressão. No segundo grupo, foram encontrados oito segmentos, sendo a maior parte produtores de bens intermediários ou de capital, como papel e celulose, metalurgia básica e máquinas e equipamentos. Os dez setores restantes apresentaram os piores indicadores, incluindo segmentos da indústria tradicional. Alguns são produtores de bens intermediários (ex: produtos de madeira), outros de bens de consumo (ex: calçados e vestuário), além de uma parcela da indústria extrativa (ex: carvão mineral e minerais não-metálicos).

A comparação entre os resultados aqui encontrados com os obtidos na literatura especializada confirma que o primeiro grupo está associado a setores com alto nível e alto crescimento da produtividade. O segundo, embora também possua em geral taxas de produtividade relativamente elevadas, tem apresentado crescimento mais baixo da produtividade no passado recente. Finalmente, o terceiro grupo possui níveis de produtividade menores que os demais. Tal resultado reforça o uso das variáveis utilizadas neste trabalho, em que foi argumentado que salários altos, maior nível de escolaridade e elevada participação de trabalhadores técnicos e científicos estavam associados a um maior nível de produtividade.

As diferenças regionais são marcantes. Muitas vezes, setores que apresentam indicadores relativamente favoráveis nas regiões mais desenvolvidas mostram situação bem pior em outras regiões. Apesar disso, foram identificados vários segmentos com uma relativa homogeneidade regional. Não se trata apenas da indústria tradicional, como couro, calçados, vestuário, têxtil, etc. Na realidade, as duas divisões mais homogêneas regionalmente fazem parte do complexo eletroeletrônico - fabricação de material eletrônico e de aparelhos e equipamentos de comunicação e fabricação de equipa- 
mentos de instrumentação para uso médico-hospitalalar - apresentando indicadores relativamente favoráveis em todo o País.

Tais resultados, se, por um lado, mostram os limites do processo de descentralização industrial em termos de obtenção de grandes avanços nas regiões menos desenvolvidas, por outro, apontam para o potencial de melhoria da indústria nas regiões mais atrasadas. Em geral, os setores mais desenvolvidos em uma determinada região também o são nas demais e vice-versa.

A principal utilidade do artigo é o desenvolvimento de medidas sintéticas para representar um fenômeno de múltiplas dimensões, permitindo comparar o nível de desenvolvimento da indústria nos diferentes setores e regiões do País. Os maiores ou menores diferenciais encontrados podem servir para sinalizar a necessidade de medidas de política econômica a serem tomadas no sentido de redução dos desequilíbrios regionais e setoriais.

Algumas extensões podem ser sugeridas a partir deste artigo. A mais natural seria a utilização de um maior nível de desagregação tanto regional quanto setorial, para que se obtenham resultados mais finos e precisos. ${ }^{27}$ Ainda nesta direção, seria desejável comparar resultados encontrados nas capitais e nas regiões metropolitanas do País com aqueles do interior, enfrentando a atual discussão de que as condições econômicas no interior do País seriam relativamente mais favoráveis para a geração de emprego industrial.

Uma segunda extensão seria a utilização de outras fontes de dados, verificando até que ponto os resultados aqui encontrados, com variáveis que representam proxies de variáveis de "resultados" das empresas, seriam corroborados com o uso de novas estatísticas industriais. A comparação com indicadores de produtividade desenvolvida na subseção 4.4 foi um primeiro passo nessa direção.

Uma terceira possibilidade seria desenvolver uma análise de médio/longo prazo para verificar as transformações existentes no período. A maior dificuldade para esse tipo de estudo são as modificações metodológicas ocorridas nas fontes de dados. No caso da RAIS, por exemplo, houve mudanças na classificação setorial em meados da década passada e novas mudanças na classificação ocupacional em 2003. A PIA do IBGE, por sua vez, também passou por grandes mudanças em meados da década passada.

Finalmente, os resultados deste artigo apontam para a necessidade de se continuar estudando a indústria de forma tão desagregada quanto possível. O Brasil representa uma grande economia com todos os tipos de desníveis por conta de sua extensão e de seus desequilíbrios regionais. Análises que não considerem tais diferenças inevitavelmente deixarão de identificar aspectos fundamentais de sua realidade. Os inúmeros trabalhos desenvolvidos nos últimos anos sobre os chamados arranjos produtivos locais (APL) reforçam a importância e interesse desse tipo de estudo. ${ }^{28}$

27 Conforme já mencionado no texto, as indústrias de transformação e extrativa mineral podem ser desagregadas em 111 grupos, fornecendo resultados bem mais precisos e detalhados. As regiões, por sua vez, podem ser subdivididas em 137 mesorregiões e 556 microrregiões.

28 Ver, por exemplo, os trabalhos desenvolvidos pela Redesist (www.redesist.ie.ufrj.br). 


\section{REFERÊNCIAS}

ANDRADE, T. A.; SERRA, R. V. Distribuição espacial para a indústria: possibilidades atuais para sua investigação. Estudos Econômicos, v. 30, n. 2, 2000.

CAIADO, A. S. C. Desconcentração industrial regional no Brasil 1985 - 1998: pausa ou retrocesso? Tese (Doutorado) - IE/UNICAMP, Campinas, 2002.

CANO, W. Concentração e desconcentração econômica regional no Brasil. Economia e Sociedade, v. 4, n. 8, 1997.

DINIZ, C. C.; CROCCO, M. A. Reestruturação econômica e impacto regional: o novo mapa da indústria brasileira. Nova Economia, v. 6, n. 1, 1996.

FERRAZ, J. C., KUPFER, D., HAGUENAUER, L. Made in Brazil: desafios competitivos para a indústria brasileira. Campus: Rio de Janeiro, 1995.

FERRAZ, J. C.; KUPFER, D.; IOOTTY, M., Competitividad industrial en Brasil: 10 Años después de la liberalización. Revista da CEPAL, n. 82, 2004.

KUBRUSLY, L. S. Um procedimento para calcular índices a partir de uma base de dados multivariados. Revista Pesquisa Operacional, v. 21, n. 1, 2001.

KUPFER, D.; ROCHA, C. Dinâmica da produtividade e heterogeneidade estrutural na indústria brasileira. In: SEMINÁRIO EL RETO DE ACELERAR EL CRECIMIENTO EN AMÉRICA LATINA Y EL CARIBE. Santiago de Chile: CEPAL, 2004.

PACHECO, C. A. Novos padrões de localização industrial? Tendências recentes dos indicadores de produção e do investimento industrial. Brasília: IPEA, 1999. (Texto para Discussão n. 633).

RAMOS, L.; FERREIRA, V. Geração de empregos e realocação espacial no mercado de trabalho brasileiro: 1992-2002. Pesquisa e Planejamento Econômico, v. 35, n. 1, 2005a.

, V. Padrão espacial da evolução do emprego formal - 1995-2003, Rio de Janeiro: IPEA, 2005b. (Texto para Discussão n. 1102).

REZENDE, M.; WILLIE, R. Aglomeração industrial no Brasil: um estudo empírico. Estudos Econômicos, v. 35, n. 3, 2005.

SABOIA, J. Desconcentração industrial no Brasil nos anos 90: um enfoque regional. Pesquisa e Planejamento Econômico, v. 30, n. 1, 2000.

. Descentralização industrial no Brasil na década de noventa: um processo dinâmico e diferenciado regionalmente. Nova Economia, v. 11, n. 2, 2001.

SALM, C.; SABOIA, J., CARVALHO, P. Produtividade na indústria brasileira - questões metodológicas e novas evidências empíricas. Pesquisa e Planejamento Econômico, v. 27, n. 2, 1997.

SENAI. Caracterização das admissões na indústria. Brasília, 2007. 